\title{
Crystal structure of the swine-origin A (H1N1)- 2009 influenza A virus hemagglutinin (HA) reveals similar antigenicity to that of the 1918 pandemic virus
}

\author{
Wei Zhang ${ }^{1,2}$, Jianxun $\mathrm{Qi}^{1}$, Yi Shi ${ }^{1,2}$, Qing $\mathrm{Li}^{1,2,3}$, Feng Gao ${ }^{4}$, Yeping Sun ${ }^{1}$, Xishan $\mathrm{Lu}^{1,5}$, Qiong $\mathrm{Lu}^{1,2}$, \\ Christopher J. Vavricka ${ }^{1}$, Di Liu ${ }^{1,6}$, Jinghua Yan ${ }^{1}$, George F. Gao ${ }^{1,2,7 凶}$ \\ ${ }^{1}$ CAS Key Laboratory of Pathogenic Microbiology and Immunology, Institute of Microbiology, Chinese Academy of Sciences, \\ Beijing 100101, China \\ ${ }^{2}$ Graduate University, Chinese Academy of Sciences, Beijing 100049, China \\ ${ }^{3}$ College of Life Science, University of Science and Technology of China, Hefei 230027, China \\ ${ }^{4}$ Institute of Biophysics, Chinese Academy of Sciences, Beijing 100101, China \\ ${ }^{5}$ College of Veterinary Medicine, China Agricultural University, Beijing 100094, China \\ ${ }_{7}^{6}$ Network Information Center, Institute of Microbiology, Chinese Academy of Sciences, Beijing 100101, China \\ ${ }^{7}$ Beijing Institutes of Life Science, Chinese Academy of Sciences, Beijing 100101, China \\ \ Correspondence: gaof@im.ac.cn \\ Received April 22, 2010 Accepted May 5, 2010
}

\section{ABSTRACT}

Influenza virus is the causative agent of the seasonal and occasional pandemic flu. The current H1N1 influenza pandemic, announced by the WHO in June 2009, is highly contagious and responsible for global economic losses and fatalities. Although the H1N1 gene segments have three origins in terms of host species, the virus has been named swine-origin influenza virus (S-OIV) due to a predominant swine origin. 2009 S-OIV has been shown to highly resemble the 1918 pandemic virus in many aspects. Hemagglutinin is responsible for the host range and receptor binding of the virus and is therefore a primary indicator for the potential of infection. Primary sequence analysis of the 2009 S-OIV hemagglutinin (HA) reveals its closest relationship to that of the 1918 pandemic influenza virus, however, analysis at the structural level is necessary to critically assess the functional significance. In this report, we report the crystal structure of soluble hemagglutinin $\mathrm{H} 1(09 \mathrm{H} 1)$ at $2.9 \mathrm{~A}$, illustrating that the $09 \mathrm{H} 1$ is very similar to the 1918 pandemic HA $(18 \mathrm{H} 1)$ in overall structure and the structural modules, including the five defined antiboby (Ab)-binding epitopes. Our results provide an explanation as to why sera from the survivors of the 1918 pandemics can neutralize the 2009 S-OIV, and people born around the 1918 are resistant to the current pandemic, yet younger generations are more susceptible to the $\mathbf{2 0 0 9}$ pandemic.

KEYWORDS Influenza virus, pandemic, 2009, 1918, S-OIV, hemagglutinin (HA), structure

\section{INTRODUCTION}

In April 2009, severe flu-like human cases were reported in Mexico and the causative virus was soon identified as the influenza $A$ virus (CDC, 2009). The virus spread rapidly to the USA and was recognized as a new reassortant with three genetic lineages, mainly with a swine origin, and was therefore called swine-origin influenza virus (S-OIV) (Chang et al., 2009). Due to its extremely rapid human-to-human transmission rate, 2009 S-OIV was detected throughout the entire world within two months and the World Health Organization (WHO) declared an official pandemic on June 11th, 2009, the first pandemic in the 21st century (WHO, 2009).

Influenza virus is a negative-strand segmented RNA virus classified into Family Orthomyxoviridae, which is comprised of three types of influenza virus, A, B and C (Fields et al., 
2007). Among them, influenza $A$ viruses are the major cause of the seasonal flu and occasional pandemics. There are 8 gene segments in the influenza A virus genome, encoding 11 proteins (Fields et al., 2007; Neumann et al., 2009). They are known as HA, NA, NS1, NS2, M1, M2, PA, PB1, PB2 and $P B 1-F 2$. Hemagglutinin $(H A)$ is the major influenza virus surface envelope protein with 16 known serotypes and it is responsible for the host-range, receptor binding, stimulating host neutralization-antibody response and some additional functions. Neuraminidase (NA), with 9 subtypes that have been found to date, is the key component functioning in virus release. Gene segment exchanges (gene reassortment) from different virus origins lead to the emergence of new viruses. Current S-OIV (2009 H1N1 influenza virus) is a triple reassortment (in terms of host-origin) of influenza gene segments, with PA and PB2 from avian, PB1 from human and $\mathrm{HA}, \mathrm{NP}, \mathrm{NS}, \mathrm{NA}$ and $\mathrm{M}$ from classical/Eurasian swine (Dawood et al., 2009; Smith et al., 2009; Gao and Sun, 2010). This current $\mathrm{H} 1 \mathrm{~N} 1$ virus has been found to have many similar properties to the 1918 pandemic $\mathrm{H} 1 \mathrm{~N} 1$ virus, including the overall similarity of the genome and characteristics of pathogenesis (Itoh et al., 2009; Shen et al., 2009; WHO, 2009; Yang et al., 2009; Igarashi et al., 2010; Yeping Sun et al., 2010).

Influenza A virus infects the host cell by way of endocytosis mediated by the binding of HA to sialic acid receptors (either 2, 3 or 2, 6 linked (reviewed in Liu et al., 2009)). Following the fusion between the virus and endosomal membrane at low $\mathrm{pH}$, viral RNA is released into the cytoplasm and the virus is able to replicate (Skehel and Wiley, 2000). Binding of HA to its receptor initiates this infection process and is therefore a major target for the host immune system and the major component of influenza vaccine.

$\mathrm{HA}$ is initially translated as a precursor ( $\mathrm{HAO})$ and is cleaved by host proteases into two subunits, HA1 and HA2, which form the functional protein. The structural basis for the function of the HA trimer in both its $\mathrm{HA} 0$ and $\mathrm{HA} 1 / \mathrm{HA} 2$ forms has previously been solved by Wiley and colleagues (Wilson et al., 1981; Chen et al., 1998). To elucidate the molecular characteristics of HA from the 2009 S-OIV $(09 H 1)$ in comparison with other HAs, especially the $1918 \mathrm{HA}(18 \mathrm{H} 1)$, we took the advantage of soluble transmembrane-removed recombinant $\mathrm{HA}$ for structural studies. Here we report the $09 \mathrm{H} 1$ structure at $2.9 \AA$ in comparison with $1918 \mathrm{H} 1$. The results not only provide the structural basis of the suspected similarity between the $09 \mathrm{H} 1$ and $18 \mathrm{HA}$ but also reveal some $09 \mathrm{H} 1$ distinct characteristics including the basic patches and $\mathrm{N}$-glycosylation of N279.

\section{RESULTS}

\section{The overall structure of soluble $09 \mathrm{H} 1$}

The soluble 09H1 (A/California/04/2009) was prepared based on the method described by Stevens et al. in a baculovirus expression system (Stevens et al., 2004, 2006; Ekiert et al., 2009). The construct incorporated a C-terminal thrombin cleavage site, a trimerizing sequence ('foldon') and a hexa His-tag at the extreme $\mathrm{C}$ terminus of the construct to enable protein purification. Although protein was theoretically expressed as a trimer (Fig. 1), only monomers were purified by gel filtration after foldon removal by the thrombin cleavage step, judged by gel-filtration molecular weight estimation (Fig. 1). However, monomer preparations were still able to reform trimers in the crystal state and the HA1 and HA2 have been cleaved in our observed structure although over $90 \%$ of the protein preparations are uncleaved $\mathrm{HAO}$ during the protein preparation process (Fig. 1).

Crystals of the $09 \mathrm{H} 1$ protein were grown using the hangingdrop diffusion method at $\mathrm{pH} 6.5$ and $18^{\circ} \mathrm{C}$. The structure was
A

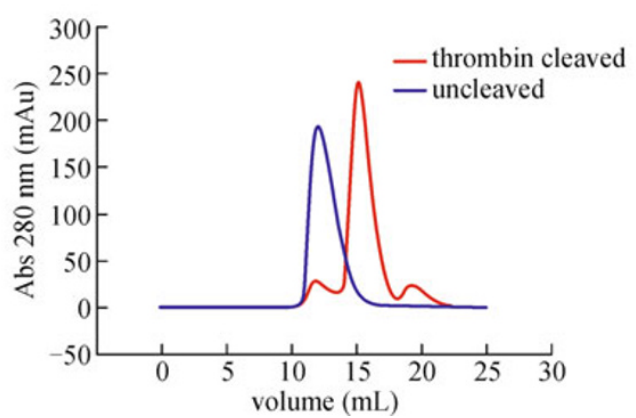

B

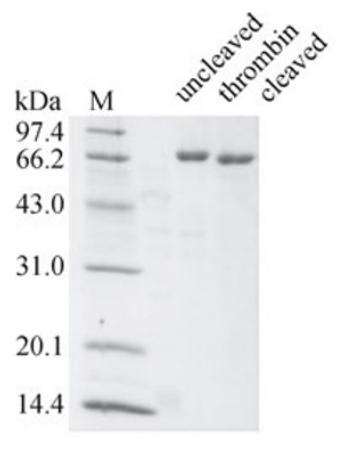

Figure 1. Gel filtration and SDS-PAGE analysis of $09 \mathrm{H} 1$. (A) The initially expressed $09 \mathrm{H} 1$ protein eluted as a trimer (blue line) by size exclusion chromatography on a Superdex-200 10/300 GL column (GE Healthcare), after thrombin cleavage, the protein behaved as a monomer (red trace) but yielded quality crystals as a trimer. (B) Uncleaved HA protein ran as a $70 \mathrm{kDa}$ protein on an SDS-PAGE gel while thrombin cleaved $09 \mathrm{H} 1$ ran as a $65 \mathrm{kDa}$ protein. The decrease in size was due to the removal of the foldon trimerizing domain from the $\mathrm{C}$ terminus. 
solved at $2.9 \AA$ by molecular replacement using the 1934-HA (PDB code 1RU7) as a search model. Crystallographic statistics are given in Table 1. The overall structure of the $09 \mathrm{H} 1$ (Fig. 2) is highly similar to all the solved HA structures to date (Yeping Sun et al., 2010) which is in accordance to the soluble $18 \mathrm{H} 1$ (A/South Carolina/1/18) preparation reported earlier (Stevens et al., 2004). The crystal packing is the same for the 09HA as it is in all other previously reported HA structures and the average RMSD value among the six HA molecules in an asymmetric unit is $0.489 \AA$ (calculated with LSQMAN).

\section{Striking similarity of the 5-defined antibody recognizing epitopes between $09 \mathrm{H} 1$ and $18 \mathrm{H} 1$}

To reveal the antigenicity of the $09 \mathrm{H} 1$, we studied the defined antibody-recognizing sites ( $\mathrm{Sa}, \mathrm{Sb}, \mathrm{Ca} 1, \mathrm{Ca} 2$ and $\mathrm{Cb}$ ) described earlier (Caton et al., 1982), which is important for the escape of influenza virus from host immune system surveillance. We compared these five antigenic sites with all the known HA structures of the $\mathrm{H} 1$ serotype. They are $09 \mathrm{H} 1$, $18 \mathrm{H} 1$ and $30 \mathrm{H} 1$ (swine $\mathrm{A} /$ swine/lowa/30), 34H1 (human $\mathrm{A} /$ Puerto Rico/8/34) and 05H1 (avian A/WDK/JX/12416/2005) (Gamblin et al., 2004; Lin et al., 2009). As shown in Fig. 3, human $34 \mathrm{H} 1$ is unique, in comparison with all other four animal-origin $\mathrm{H} 1 \mathrm{~s}$, which further confirms the antigenicity difference between human- and animal-origin HAs. This may be explained by differences in the immune pressures encountered in animals and humans. All the four animalorigin $\mathrm{H} 1 \mathrm{~s}$ have structurally similar antigenic sites. In detail, between $18 \mathrm{H} 1$ and $30 \mathrm{H} 1$, the following mutations occurred: S173N in Sa site, G202S and S207N in Sb site, D239G and $\mathrm{S} 154 \mathrm{P}$ in $\mathrm{Ca} 2$ site, $\mathrm{A} 90 \mathrm{~V}$ in $\mathrm{Cb}$ site (totally 6 mutations); between $18 \mathrm{H} 1$ and $09 \mathrm{H} 1$, these mutations occurred: S173N in Sa site, G202S and T203A in Sb site, N185D, V183I and K223R in Ca1 site, S159K, Y155H and S154P in Ca2 site, L88S in $\mathrm{Cb}$ site (totally 10 mutations); between $18 \mathrm{H} 1$ and $05 \mathrm{H} 1$, these mutations occurred: S173T in Sa site, G202T,

Table 1 Data collection and refinement statistics (molecular replacement)

\begin{tabular}{|c|c|}
\hline & 09HA \\
\hline \multicolumn{2}{|l|}{ data collection } \\
\hline space group & $\mathrm{P} 1$ \\
\hline \multicolumn{2}{|l|}{ cell dimensions } \\
\hline$a, b, c(\AA)$ & $66.02,115.19,114.99$ \\
\hline$\alpha, \beta, \gamma\left({ }^{\circ}\right)$ & $62.31,77.94,81.05$ \\
\hline resolution $(\AA)$ & $50-2.90(2.90-3.00)^{a}$ \\
\hline$R_{\text {sym }}$ or $R_{\text {merge }}$ & $0.105(0.501)$ \\
\hline$\| / \sigma(I)$ & $12.9(1.91)$ \\
\hline completeness (\%) & $98.0(90.7)$ \\
\hline redundancy & $3.7(2.7)$ \\
\hline \multicolumn{2}{|l|}{ refinement } \\
\hline resolution $(\AA)$ & $24.2-2.9$ \\
\hline No. reflections & 64,796 \\
\hline$R_{\text {work }} / R_{\text {free }}$ & $24.6 / 27.0$ \\
\hline \multicolumn{2}{|l|}{ No. atoms } \\
\hline protein & 22,860 \\
\hline ligand/ion & 431 \\
\hline water & 321 \\
\hline \multicolumn{2}{|l|}{$B$-factors } \\
\hline protein & 81.2 \\
\hline $\mathrm{N}$-glycosylation sites & 130.6 \\
\hline water & 68.3 \\
\hline \multicolumn{2}{|l|}{ r.m.s. deviations } \\
\hline bond lengths $(\AA)$ & 0.004 \\
\hline bond angles $\left({ }^{\circ}\right)$ & 0.971 \\
\hline
\end{tabular}

${ }^{a}$ Values in parentheses are for highest-resolution shell. 

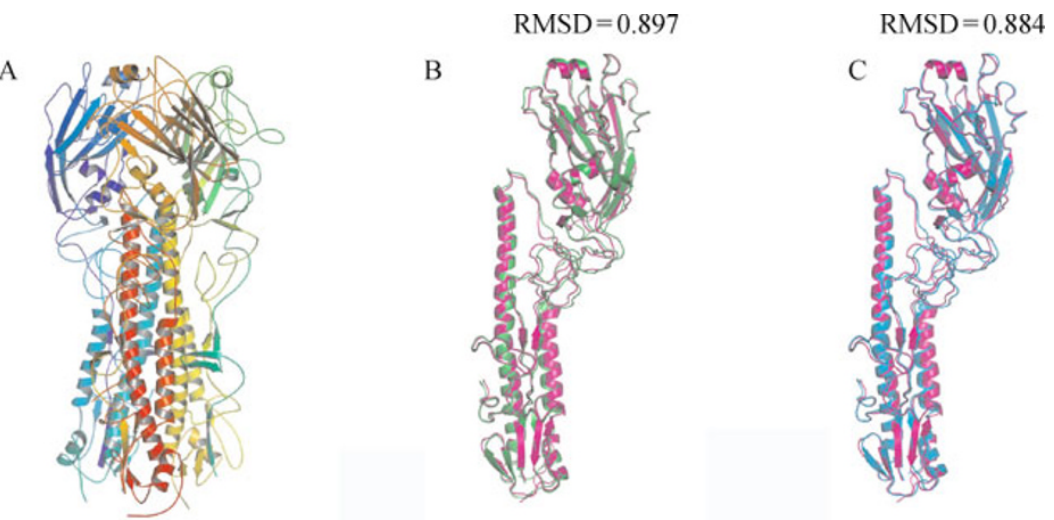

Figure 2. The $09 \mathrm{H} 1$ trimer structure and the comparison between $09 \mathrm{H} 1, \mathbf{1 8 H} 1$ and $34 \mathrm{H} 1$. (A) Overall view of the $09 \mathrm{H} 1 \mathrm{trimer}$ structure. ( $\mathrm{B}$ and $\mathrm{C}$ ) Comparison of the monomers between the $09 \mathrm{H} 1$ (magenta) and 18H1 (green) or 34H1 (blue). The RMSD values for both two comparisons are very small $(0.90$ and 0.88$)$, which shows that $09 \mathrm{H} 1$ has a very similar structure to $18 \mathrm{H} 1$ and $34 \mathrm{H} 1$ (seasonal flu).

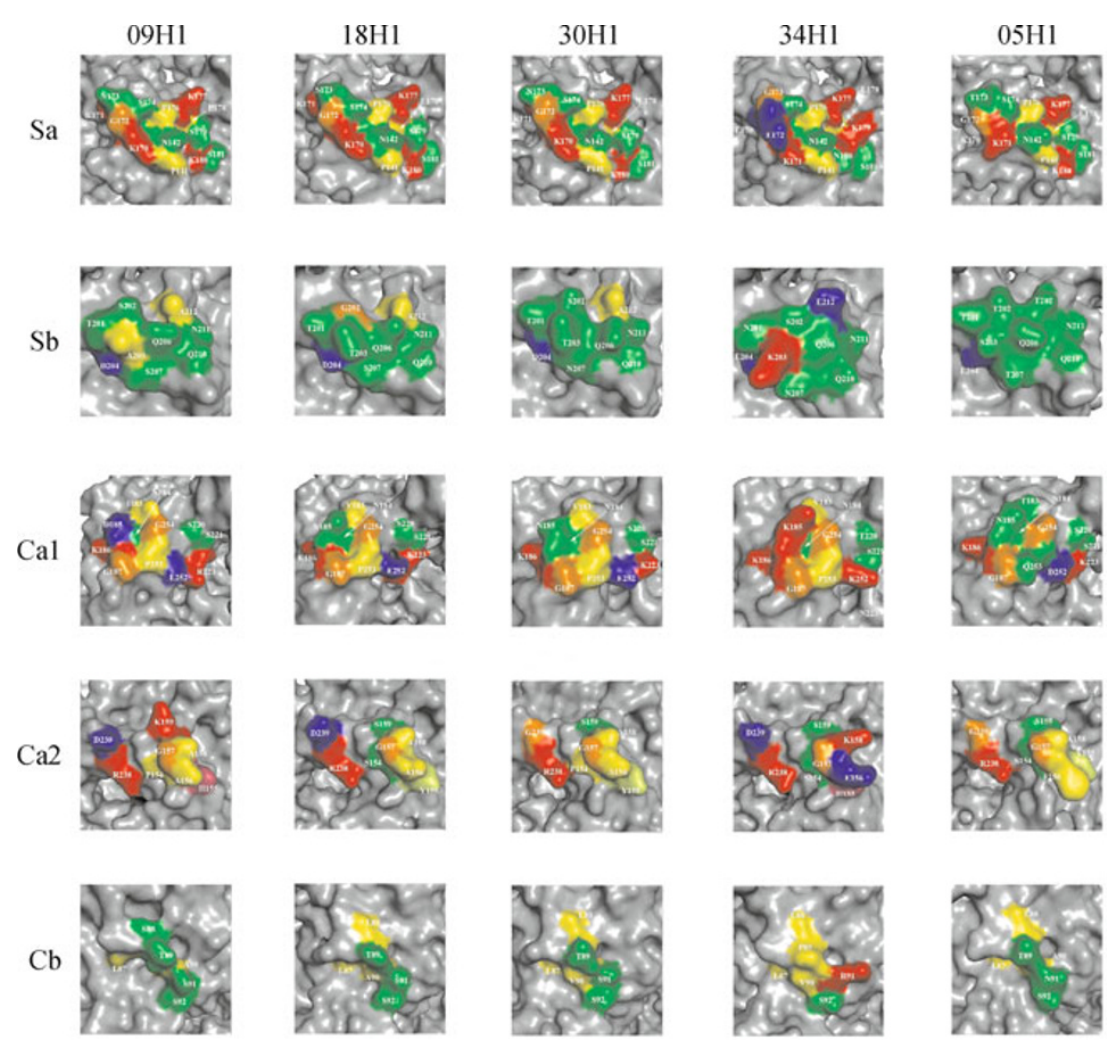

Figure 3. Highlights of the five defined antibody-epitopes ( $\mathrm{Sa}, \mathrm{Sb}, \mathrm{Ca} 1, \mathrm{Ca}, \mathrm{Cb})$ of the $09 \mathrm{H} 1 \mathrm{in}$ comparison with $18 \mathrm{H} 1$, $30 \mathrm{H} 1,34 \mathrm{H} 1$ and $05 \mathrm{H} 1$, all the known crystal structures of the $\mathrm{H} 1$ serotypes to date. Amino acids are colored by the customized ClustalX color scheme: Ala, Leu, lle, Pro, and Val (yellow); Lys and Arg (red); Asp and Glu (blue); Ser, Thr, Gln and Asn (green); His (pink); Tyr (limon); Gly (orange). It is clearly apparent that the $09 \mathrm{H} 1$ and $18 \mathrm{H} 1$ are most likely related among these $\mathrm{H} 1$ structures. All the pictures (including the pictures in other figures) were generated by PYMOL based on the crystal structures of $09 \mathrm{H} 1,18 \mathrm{H} 1,30 \mathrm{H} 1$, 34H1 and 05H1 (PDB codes: 1RUZ, 1RUY, 1RU7, 3HTO and 3LYJ, respectively).

T203S, D204E, S207T and A212T in Sb site, V183T, E252D and $\mathrm{P} 253 \mathrm{Q}$ in Ca1 site, A156F and D239G in Ca2 site, and
$\mathrm{S} 91 \mathrm{~N}$ in $\mathrm{Cb}$ site (totally 12 mutations). Thus, from 1918 to 2009 , in animals like swine and avian, the antibody-mediated 
selective pressure may be much lower than in humans due to less complex immune systems, and the amino acid residues in the antigenic sites would not change frequently which is consistent with previous studies (Sugita et al., 1991).

However, in the more complex human immune system, which has also been exposed to vaccination since the 1918 pandemic flu, the HA molecule of seasonal H1N1 flu would benefit from frequent mutation of antigenic sites (antigenic drift) as a way to escape from immune system surveillance, just as was observed in the $34 \mathrm{H} 1$ structure. It is noteworthy that $09 \mathrm{H} 1$ and $18 \mathrm{H} 1$ structures most closely resemble each other (Fig. 3) with only ten amino acid differences in the five epitopes (most of them result from similar amino acid substitutions).

\section{Strong basic patches and their implications for virus fusion}

There are two basic patches in the 09HA structure (Fig. 4). The first one is near the cleavage site, which contains three basic histidine residues (His18 and His 38 from the HA1 chain, and His111 from the HA2 chain) and this basic patch is conserved in human $\mathrm{H} 1, \mathrm{H} 2$ and $\mathrm{H} 5$ sequences (Stevens et al., 2004, 2006). While the second basic patch is a defined structural module initially found in the $18 \mathrm{H} 1$ structure, later found in other $\mathrm{H} 1 \mathrm{HA}$ structures and one H5 HA structures, but not observed in other HA structures and thought to be important for virus membrane fusion and infection (Stevens et al., 2004, 2006). Thus, we examined the second basic patch on the HA1 chain adjacent to the vestigial esterase domain. This very-basic patch is composed of four HA1 histidines (His47, His275, His285, His298) and a lysine (Lys50), in the four $\mathrm{H} 1 \mathrm{HA}$ molecules $(18 \mathrm{H} 1,30 \mathrm{H} 1,34 \mathrm{H} 1$ and $05 \mathrm{H} 1)$, as shown in Fig. 3. By contrast, the area of the basic patches (blue regions) is obviously larger in $09 \mathrm{H} 1$ than any other $\mathrm{H} 1$, including $18 \mathrm{H} 1$, due to its $\mathrm{N} / \mathrm{S} 46 \mathrm{~K}$ and $\mathrm{H} 285 \mathrm{~K}$ substitutions. Although there has been no direct evidence till now, the increased basicity of the basic patch has been proposed to be related to enhanced virus membrane fusion and subsequent pathogenicity as proposed by Stevens et al. (2004, 2006), and experimental testing of such a hypothesis is required.

\section{Extra $\mathrm{N}$-glycosylation site near the second basic patch region and $\mathrm{Cb}$ antigenic site}

The primary sequence of the soluble $09 \mathrm{H} 1$ in this analysis predicts 6 possible glycosylation sites (NXS/T) per monomer. Interpretable electron density in the complex is observed at all the potential $\mathrm{N}$-glycosylation sites in each $09 \mathrm{H} 1$ monomer (36 sites in total of the six molecules). Therefore we have determined that all potential $N$-glycosylation sites are occupied in the $09 \mathrm{H} 1$, at least in our in vitro baculovirusexpressed form, with typical $\mathrm{N}$-glycosylation structures. Compared with $18 \mathrm{H} 1$ and other $\mathrm{H} 1$ molecules (Fig. 5), a new glycosylation site at NTT (residue N279, H3 numbering) is observed near the second basic patch we mentioned above. This glycosylation likely results in steric hindrance to the second basic patch, thereby reducing the ability of the basic enzymes to interact with the basic patch, which may help the membrane-fusion of virus. Furthermore, this new glycosylation site may also interfere with antibody recognition of the $\mathrm{Cb}$ antigenic site. Clearly, it deserves further investigation in the near future.

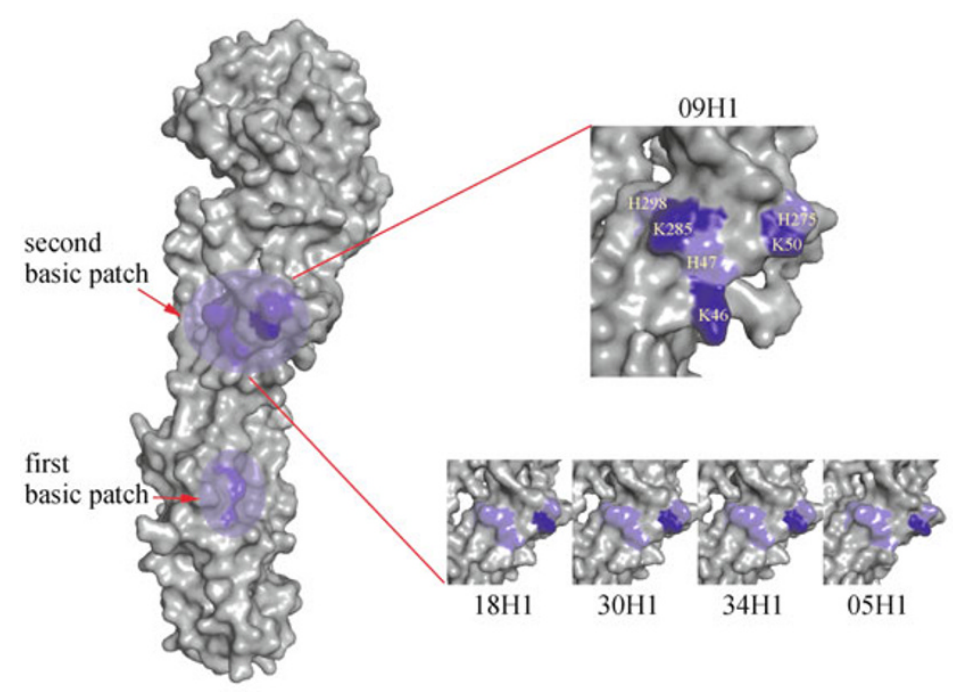

Figure 4. Comparison of the basic patches of $09 \mathrm{H} 1$ with other H1 HAs. Overview of the two basic patches (blue region) is shown on the left, and a detailed comparison of different HAs is shown on the right. Lysine is colored with dark blue, and histidine is shown in light blue. 


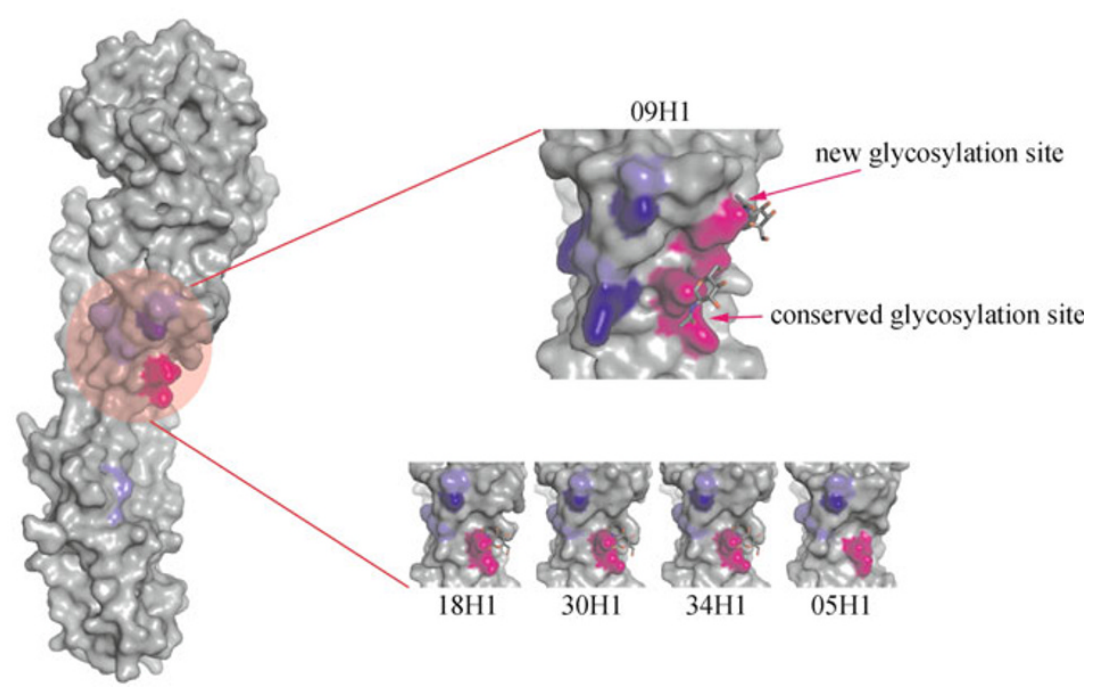

Figure 5. Comparison of the $\mathbf{N}$-glycosylation sites near the upper basic patch. A new glycosylation site is found in the $09 \mathrm{H} 1$ molecule, and the glycosylation sites are shown in magenta with the glycans represented as stick patterns.

\section{Lack of the glycosylation sites on the receptor binding proximal region (receptor binding apex) and its implications for the virus neutralizations}

Influenza virus can escape targeting by the host immune system by several ways. Two examples are discussed here. First, the virus can change its antigenic surface, which is called antigen drift. Second, the virus can evolve new glycosylation sites that allow sugars derived from the host cell to attach to the antigenic sites. These sugars can mask the antigenic sites in order to avoid the antibodies to recognize the virus. As we mentioned above, the HA molecule of the 2009 S-OIV pandemic virus has highly similar antigenic sites with 1918 pandemic virus and other animalorigin influenza viruses, and is divergent with $\mathrm{HA}$ molecules of seasonal flu which are under high pressure in the host body. With exception to the considerable pandemic divergence, the seasonal flu has evolved gradually to acquire up to three glycosylation sites near the receptor binding site (Fig. 6), and the sugars attached to these glycosylation sites can affect the ability of antibodies to recognize the amino acids within the Sa and $\mathrm{Sb}$ antigenic sites. As a result, the antibodies in the body of the young people whose immune systems are adapted to the seasonal flu tend to attack the other three antigenic sites (Ca1, Ca2 and $\mathrm{Cb}$ ). $\mathrm{Ca} 1$ and $\mathrm{Ca} 2$ sites are at the subunit interface which is unfavorable for the antibody recognition. However, the $\mathrm{Cb}$ site is within the vestigial esterase domain full of protruding loops that can be accessed readily by the antibodies. Thus, we propose that the new glycosylation site near the vestigial esterase domain in the $09 \mathrm{H} 1$ may help the swine-origin 2009 influenza virus to escape antibody recognition, partly responsible for the pandemic. Of course this requires further confirmation in the near future.

\section{DISCUSSION}

Our crystal structure of the soluble 09HA, together with a recent publication during our preparation of this manuscript (Xu et al., 2010), demonstrates that $09 \mathrm{H} 1$ has very similar antigenic sites with $18 \mathrm{H} 1$, but is distinct from the seasonal flu viruses, indicating that the pandemic ( $\mathrm{H} 1 \mathrm{~N} 1)$ influenza virus (2009 S-OIV H1N1) can be neutralized by the antibody from people who have been infected with 1918 pandemic influenza virus. This might explain why younger people are more susceptible to the current virus, but the people who experienced the 1918 pandemic are more resistant to the current pandemic virus (Itoh et al., 2009). The lack of the cross-antigenicity with the decades' seasonal flu HAs might also explain how the 2009 S-OIV can spread so rapidly to a pandemic level. We can predict that in the future, under the pressure of the host immunity, the 2009 S-OIV will evolve to similar seasonal flu just as the 1918 influenza virus did from 1918 to 2009.

A stronger basic patch may increase the infectivity of the influenza virus, while the new N-glycosylation site (N279) near the stronger basic patch may reduce its function. If the infectivity of the influenza virus is too high, it may kill the host before it is able to spread. Therefore, we speculate that the stronger basic patch and new glycosylation site may be an evolutionary balance for the infectivity of the 2009 S-OIV and might help the virus to survive in the host.

Recently, it has been suggested that the focus of immune system response can be changed by modification of glycosylation sites in the HA protein (Wei et al., 2010). The addition of a new $\mathrm{N}$-glycosylation site (N279) within the vestigial esterase domain, which is not observed in the 1918 H1 HA, may facilitate world-wide transmission of the swine- 
A

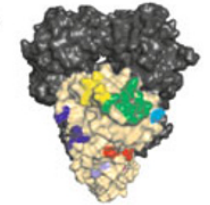

1918-H1

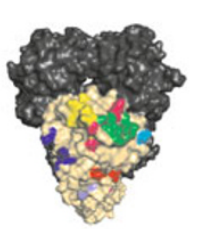

1977-H1

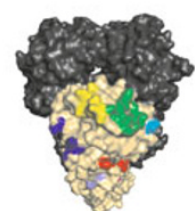

1934-H1

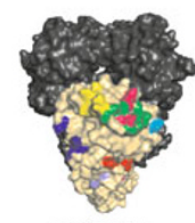

2007-H1

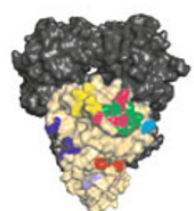

1957-H1
B

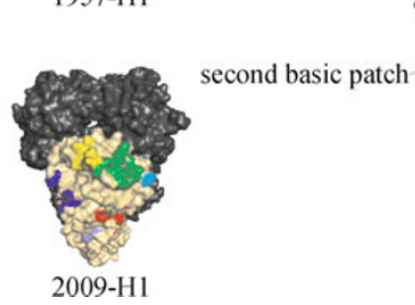

Sa Sb

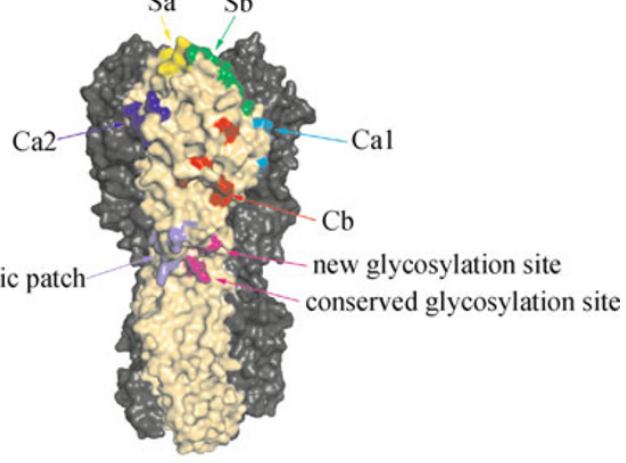

Figure 6. Analysis of 09HA $\mathrm{N}$-glycosylation sites. (A) Comparison of the $\mathrm{N}$-glycosylation sites on the head of HA molecules between swine-origin flu and seasonal flu from 1918 to 2009. Glycosylation sites on the head of HA molecules are not present in $09 \mathrm{H} 1$ and $18 \mathrm{H} 1$, while in $\mathrm{HA}$ from the seasonal flu $(1957-\mathrm{H} 1,1977-\mathrm{H} 1,2007-\mathrm{H} 1)$ there are up to three glycosylation sites (with exception to 1934-H1). Only the structures of 1957-H1 (A/Denver/57), 1977-H1 (A/USSR/90/1977), and 2007-H1 (A/Brisbane/59/ 2007) were modeled for comparison, as structures for all the $\mathrm{H} 1 \mathrm{HAs}$ are very similar. Glycosylation sites on the head are marked in hot pink color. (B) Closer view of the the $\mathrm{N} 279 \mathrm{~N}$-glycosylation site, the second basic patch and the five antigenic sites of $09 \mathrm{H} 1$. The recognition of the antibody specific to the $\mathrm{Cb}$ sites can be affected by the presence of glycans in this region.

origin 2009 pandemic virus by interfering with antibody recognition specific to the $\mathrm{Cb}$ site. Thus, people who are adapted to seasonal HA will likely be less resistant to the 2009 pandemic virus than influenza strains originating from the 1918 virus, which do not possess this $\mathrm{N}$-glycosylation site.

In conclusion, our structural analyses of the 2009 pandemic HA show its true similarity to the 1918 pandemic $\mathrm{HA}$. The new $\mathrm{N}$-glycosylation site and strong second basic patch of the 2009 HA might contribute to the rapid human-tohuman transmission and high virulence, which deserves further experimental work in the future.

\section{MATERIALS AND METHODS}

\section{Cloning, expression and purification of $09 \mathrm{H} 1$}

Methods for the cloning, expression and purification of secreted $09 \mathrm{H} 1$ were based on those reported by Stevens et al. $(2004,2006)$ and Ekiert et al. (2009). Briefly, cDNA encoding amino acid residues 11-505 (11-329 (HA1) and 1-176 (HA2)) from the A/California/04/ 2009 HA ectodomain was amplified and cloned into the baculovirus transfer vector pAcGP67-B (BD Biosciences), containing a thrombin cleavage site, a trimerizing 'foldon' sequence and a his-tag.

The recombinant transfer vector and BaculoGold ${ }^{\mathrm{TM}}$ linearized viral DNA (BD Biosciences) were co-transfected into log phase Sf9 cells using CellfectinR Reagent (Invitrogen). Sf9 cells were grown in suspension using Sf-900II SFM serum-free media (Invitrogen) at $28^{\circ} \mathrm{C}$ and 120 RPM. A high-titer viral stock of pure recombinant virus was generated through amplification in suspension cultured Sf9 cells.

Sf9 suspension cultures were transfected with high tighter baculovirus and grown for $3 \mathrm{~d}$. Cells and debris were removed from the sample by centrifugation at $4000 \mathrm{~g}$ for $40 \mathrm{~min}$ and the subsequent growth media was applied to a HisTrap FF 5-mL column (GE Health). After elution with $300 \mathrm{mM}$ imidazole, combined HA fractions were dialyzed against $10 \mathrm{mM}$ Tris- $\mathrm{HCl}, 50 \mathrm{mM} \mathrm{NaCl}, \mathrm{pH} 8.0$ and then further separated using a Mono-Q 4.6/100 PE column (GE Health).

The HA protein was then subjected to thrombin digest (Sigma, 3 units/mg $\mathrm{HA}$; overnight at $4^{\circ} \mathrm{C}$ ) followed by gel filtration chromatography using a Superdex-200 10/300 GL column (GE Healthcare) with $20 \mathrm{mM}$ Tris- $\mathrm{HCl}, 50 \mathrm{mM} \mathrm{NaCl}, \mathrm{pH} 8.0$ as running buffer. After final processing with thrombin, the recombinant $\mathrm{HA}$ includes additional amino acid residues (RLVPR) at the C-terminal. The protein also contains additional $\mathrm{N}$-terminal residues (ADLGSR) encoded by the plasmid. Fractions containing highly pure HA were pooled and concentrated to $5 \mathrm{mg} / \mathrm{mL}$ using a membrane concentrator with a molecular weight cutoff of 10,000 (Millipore).

\section{Crystallization and data collection}

09H1 crystals were grown using the hanging-drop diffusion method with a reservoir solution $(0.4 \mathrm{~mL})$ of $10 \%$ PEG $6000,5 \% \mathrm{MPD}, 0.1 \mathrm{M}$ MES, pH 6.5. Crystallization drops were set up at $18^{\circ} \mathrm{C}$, with $1.5 \mu \mathrm{L}$ of protein mixed with an equal volume of reservoir solution. Crystals appeared in approximately one month. The resulting crystals were cryoprotected by soaking in $2 \mu \mathrm{L}$ well solution mixed with $1 \mu \mathrm{L} 50 \%$ PEG 6000, then flash-cooled in a cold nitrogen-gas stream at $100 \mathrm{~K}$. X-ray diffraction data were collected on Shanghai Synchrotron Radiation Facility (SSRF) beamline $17 \mathrm{U}$ at a wavelength of $0.9795 \AA$.

\section{Data processing, molecular replacement and structure refinement}

The data were processed and scaled by using the HKL2000 (Otwinowski and Minor, 1997). The structure of 09H1 was solved at $2.9 \AA$ by the molecular replacement method using Phaser (Read, 2001) from the CCP4 program suite (CCP4, 1994) (Collaborative Computational Project, Number 4) with the structure of 34H1 (PDB ID 1 RU7) as the search model. Extensive model building and restrained 
refinement were performed using COOT (Emsley and Cowtan, 2004) and REFMAC5 (Murshudov et al., 1997). The Further rounds of refinement were performed using the Phenixrefine program implemented in the PHENIX package (Adams et al., 2002) with isotropic ADP refinement and bulk solvent modeling with NCS restriction. The final model has an $R_{\text {work }}$ of $24.6 \%$ and an $R_{\text {free }}$ of $27.0 \%$. The stereochemical quality of the final model was assessed with the program PROCHECK (Laskowski et al., 1993). 81.3\% of the peptide bonds were present in the most favored region of the Ramachandron plot, $18.4 \%$ in the additionally allowed region and $0.3 \%$ in the generally allowed region.

\section{PROTEIN DATA BANK ACCESSION CODES}

Atomic coordinates and structure factors for the reported crystal structure have been deposited with the Protein Data Bank accession number $3 L Y J$. Correspondence and requests for reprints and materials should be addressed to G.F.G. (gaof@im.ac.cn).

\section{ACKNOWLEDGMENTS}

We thank Ms. Hui Niu (NIBS), Dr. Jijie Chai (NIBS), Dr. Jinsong Liu (GIBH, CAS), Dr. Zhijie Liu (IBP, CAS) and Dr. Maojun Yang (Tsinghua University) for help in performing the experiments. Assistance by the staff (esp. Dr. Sheng Huang and Dr. Jianhua He) at Shanghai Synchrotron Radiation Facility (SSRF-beamline 17U) is acknowledged. This work is supported by the intramural grant of the Chinese Academy of Sciences (Grant No. KSCX2-YW-R-158), the National Basic Research Program (973 Program) (Grant Nos. 2010CB534004 and 2005CB523001). G.F.G. is a distinguished young investigator of the NSFC (Grant No. 30525010). Dr. Christopher Vavricka is, partly, supported by the Fellowship for Young International Scientists of the Chinese Academy of Sciences (Grant No. 2009Y2BS2).

\section{ABBREVIATIONS}

05H1, $2005 \mathrm{H} 1 ; 09 \mathrm{H} 1,2009 \mathrm{H} 1 ; 18 \mathrm{H} 1,1918 \mathrm{H} 1 ; 34 \mathrm{H} 1,1934 \mathrm{H} 1 ; \mathrm{HA}$, hemagglutinin; NA, neuraminidase; S-OIV, swine-origin influenza virus

\section{REFERENCES}

Adams, P.D., Grosse-Kunstleve, R.W., Hung, L.W., loerger, T.R., McCoy, A.J., Moriarty, N.W., Read, R.J., Sacchettini, J.C., Sauter, N.K., and Terwilliger, T.C. (2002). PHENIX: building new software for automated crystallographic structure determination. Acta Crystallogr D Biol Crystallogr 58, 1948-1954.

Caton, A.J., Brownlee, G.G., Yewdell, J.W., and Gerhard, W. (1982). The antigenic structure of the influenza virus $A / P R / 8 / 34$ hemagglutinin ( $\mathrm{H} 1$ subtype). Cell 31, 417-427.

Centers for Disease Control and Prevention (CDC). (2009). Outbreak of swine-origin influenza A (H1N1) virus infection- Mexico, MarchApril 2009. MMWR Morb Mortal Wkly Rep 58, 467-470.

Chang, L.Y., Shih, S.R., Shao, P.L., Huang, D.T., and Huang, L.M. (2009). Novel swine-origin influenza virus $A(H 1 N 1)$ : the first pandemic of the 21st century. J Formos Med Assoc 108, 526-532.

Chen, J., Lee, K.H., Steinhauer, D.A., Stevens, D.J., Skehel, J.J., and Wiley, D.C. (1998). Structure of the hemagglutinin precursor cleavage site, a determinant of influenza pathogenicity and the origin of the labile conformation. Cell 95, 409-417.

Collaborative Computational Project, Number 4. (1994). The CCP4 suite: programs for protein crystallography. Acta Crystallogr D Biol Crystallogr 50, 760-763.

Dawood, F.S., Jain, S., Finelli, L., Shaw, M.W., Lindstrom, S., Garten, R.J., Gubareva, L.V., Xu, X., Bridges, C.B., and Uyeki, T.M., and the Novel Swine-Origin Influenza A (H1N1) Virus Investigation Team. (2009). Emergence of a novel swine-origin influenza $A$ (H1N1) virus in humans. N Engl J Med 360, 2605-2615.

Ekiert, D.C., Bhabha, G., Elsliger, M.A., Friesen, R.H., Jongeneelen, M., Throsby, M., Goudsmit, J., and Wilson, I.A. (2009). Antibody recognition of a highly conserved influenza virus epitope. Science 324, 246-251.

Emsley, P., and Cowtan, K. (2004). Coot: model-building tools for molecular graphics. Acta Crystallogr D Biol Crystallogr 60, 2126-2132.

Fields, B.N., Knipe, D.M., and Howley, P.M. (2007). Fields virology, 5th edn (Philadelphia, Wolters Kluwer Health/Lippincott Williams \& Wilkins).

Gamblin, S.J., Haire, L.F., Russell, R.J., Stevens, D.J., Xiao, B., Ha, Y., Vasisht, N., Steinhauer, D.A., Daniels, R.S., Elliot, A., et al. (2004). The structure and receptor binding properties of the 1918 influenza hemagglutinin. Science 303, 1838-1842.

Gao, G.F., and Sun, Y.P. (2010). It is not just AIV: from avian to swineorigin influenza virus. Sci China C Life Sci 53, 151-153.

Igarashi, M., Ito, K., Yoshida, R., Tomabechi, D., Kida, H., Takada, A., and Belshaw, R. (2010). Predicting the antigenic structure of the pandemic (H1N1) 2009 influenza virus hemagglutinin. PLoS ONE 5, e8553.

Itoh, Y., Shinya, K., Kiso, M., Watanabe, T., Sakoda, Y., Hatta, M., Muramoto, Y., Tamura, D., Sakai-Tagawa, Y., Noda, T., et al. (2009). In vitro and in vivo characterization of new swine-origin H1N1 influenza viruses. Nature 460, 1021-1025.

Laskowski, R.A., MacArthur, M.W., Moss, D.S., and Thornton, J.M. (1993). PROCHECK: A program to check the stereochemical quality of protein structures. J Appl Cryst 26, 283-291.

Lin, T., Wang, G., Li, A., Zhang, Q., Wu, C., Zhang, R., Cai, Q., Song, W., and Yuen, K.Y. (2009). The hemagglutinin structure of an avian H1N1 influenza A virus. Virology 392, 73-81.

Liu, D., Liu, X., Yan, J., Liu, W.J., and Gao, G.F. (2009). Interspecies transmission and host restriction of avian H5N1 influenza virus. Sci China C Life Sci 52, 428 438.

Murshudov, G.N., Vagin, A.A., and Dodson, E.J. (1997). Refinement of macromolecular structures by the maximum-likelihood method. Acta Crystallogr D Biol Crystallogr 53, 240-255.

Neumann, G., Noda, T., and Kawaoka, Y. (2009). Emergence and pandemic potential of swine-origin $\mathrm{H} 1 \mathrm{~N} 1$ influenza virus. Nature 459, 931-939.

Otwinowski, Z., and Minor, W. (1997). Processing of X-ray diffraction data collected in oscillation mode. Methods Enzymol 276, 307-326.

Read, R.J. (2001). Pushing the boundaries of molecular replacement with maximum likelihood. Acta Crystallogr D Biol Crystallogr 57, 1373-1382.

Shen, J., Ma, J., Wang, Q., and Martin, D.P. (2009). Evolutionary trends of $A(H 1 N 1)$ influenza virus hemagglutinin since 1918. PLoS ONE 4, e7789. 
Skehel, J.J., and Wiley, D.C. (2000). Receptor binding and membrane fusion in virus entry: the influenza hemagglutinin. Annu Rev Biochem 69, 531-569.

Smith, G.J., Vijaykrishna, D., Bahl, J., Lycett, S.J., Worobey, M., Pybus, O.G., Ma, S.K., Cheung, C.L., Raghwani, J., Bhatt, S., et al. (2009). Origins and evolutionary genomics of the 2009 swineorigin H1N1 influenza A epidemic. Nature 459, 1122-1125.

Stevens, J., Corper, A.L., Basler, C.F., Taubenberger, J.K., Palese, P., and Wilson, I.A. (2004). Structure of the uncleaved human $\mathrm{H} 1$ hemagglutinin from the extinct 1918 influenza virus. Science 303, 1866-1870.

Stevens, J., Blixt, O., Tumpey, T.M., Taubenberger, J.K., Paulson, J. C., and Wilson, I.A. (2006). Structure and receptor specificity of the hemagglutinin from an H5N1 influenza virus. Science 312 , 404- 410 .

Sugita, S., Yoshioka, Y., Itamura, S., Kanegae, Y., Oguchi, K., Gojobori, T., Nerome, K., and Oya, A. (1991). Molecular evolution of hemagglutinin genes of H1N1 swine and human influenza $A$ viruses. J Mol Evol 32, 16-23.
Sun, Y., Shi, Y., Zhang, W., Li, Q., Liu, D., Vavricka, C., Yan, J., and Gao, G.F. (2010). In-silicon characterization of the functional and structural modules of the haemagglutinin protein from the swineorigin influenza virus A (H1N1)-2009. Sci China C Life Sci.

Wei, C.J., Boyington, J.C., Dai, K., Houser, K.V., Pearce, M.B., Kong, W.P., Yang, Z.Y., Tumpey, T.M., and Nabel, G.J. (2010). Crossneutralization of 1918 and 2009 influenza viruses: role of glycans in viral evolution and vaccine design. Sci Transl Med 2, 24ra21.

WHO (2009). World now at the start of 2009 influenza pandemic.

Wilson, I.A., Skehel, J.J., and Wiley, D.C. (1981). Structure of the haemagglutinin membrane glycoprotein of influenza virus at $3 \AA$ resolution. Nature 289, 366-373.

Xu, R., Ekiert, D.C., Krause, J.C., Hai, R., Crowe, J.E. Jr, and Wilson, I.A. (2010). Structural Basis of Preexisting Immunity to the 2009 H1N1 Pandemic Influenza Virus. Science 328, 357-60.

Yang, Y., Sugimoto, J.D., Halloran, M.E., Basta, N.E., Chao, D.L., Matrajt, L., Potter, G., Kenah, E., and Longini, I.M. Jr. (2009). The transmissibility and control of pandemic influenza A ( $\mathrm{H} 1 \mathrm{~N} 1)$ virus. Science 326, 729-733. 